\title{
The status of refractive errors in elementary school children in South Jeolla Province, South Korea
}

This article was published in the following Dove Press journal:

Clinical Optometry

8 July 2015

Number of times this article has been viewed

\author{
Jung Un Jang' \\ Inn-Jee Park ${ }^{2}$ \\ 'Department of Optometry, Eulji \\ University, Seongnam, ${ }^{2}$ Department \\ of Optometry, Kaya University, \\ Gimhae, South Korea
}

Purpose: To assess the prevalence of refractive errors among elementary school children in South Jeolla Province of South Korea.

Methods: The subjects were aged 8-13 years; a total of 1,079 elementary school children from Mokpo, South Jeolla Province, were included. In all participants, uncorrected visual acuity and objective and subjective refractions were determined using auto Ref-Keratometer and phoropter. A spherical equivalent of -0.50 diopter (D) or worse was defined as myopia, $+0.50 \mathrm{D}$ or more was defined as hyperopia, and a cylinder refraction greater than $0.75 \mathrm{D}$ was defined as astigmatism.

Results: Out of 1,079 elementary school children, the prevalence of uncorrected, best-corrected, and corrected visual acuity with own spectacles of $20 / 40$ or worse in the better eye was $26.1 \%$, $0.4 \%$, and $20.2 \%$, respectively. The uncorrected visual acuity was $20 / 200$ or worse in the better eye in $5.7 \%$ of school children, and $5.2 \%$ of them already wore corrective spectacles. The prevalence of myopia, hyperopia, and astigmatism was $46.5 \%$ (95\% confidence interval [CI]: 43.56-49.5), 6.2\% (95\% CI: 4.92-7.81), and 9.4\% (95\% CI: 7.76-11.25), respectively.

Conclusion: The present study reveals a considerably higher prevalence of refractive error among elementary school children in South Jeolla Province of South Korea, exceeding 50\% of subjects. The prevalence of myopia in the school children in Korea is similar to many other countries including People's Republic of China, Malaysia, and Hong Kong. This may indicate that genetics and educational influences, such as studying and learning, may play a role in the progression of myopia in Korean elementary school children.

Keywords: refractive error, elementary school children, visual acuity, myopia, astigmatism

\section{Introduction}

Refractive errors (myopia, hyperopia, and astigmatism) were one of the most common causes of visual impairment around worldwide. ${ }^{1,2}$ The refractive errors were reported to be prevalent in $>40 \%$ of students and $60 \%$ of adults. ${ }^{3-9}$ The refractive errors are one of the leading causes of visual impairment and blindness, particularly in school children. ${ }^{10}$ In order to reduce the occurrence of avoidable visual impairment caused by refractive errors, it is necessary to obtain information on visual acuity and refractive errors among school children. Recent studies from People's Republic of China (Shunyi district and Shandong), Iran, Taiwan, Nepal, Malaysia, and Chile reported the prevalence of refractive errors, especially myopia. ${ }^{11-17}$ In South Korea, there were studies on the prevalence of myopia in a sample population of 19-year olds. According to Jung et al, the prevalence of myopia in Seoul was significantly high, $96.5 \% .{ }^{18}$ Also, in Lee et al's study, the prevalence of myopia was $83.3 \% .{ }^{19}$ Lee et al reported that the
Correspondence: Jung Un Jang Department of Optometry, Eulji University, Sanseong-daero, Sujeong-gu, Seongnam 46I-7/3, Gyeonggi-do, South Korea Tel +82 3I 7407490 Email jju@eulji.ac.kr 
prevalence of high myopia was $12.39 \%$ in Busan, Ulsan, and Gyeongsangnam-do. ${ }^{20}$ However, a study on the prevalence of the refractive errors among the elementary school children in the area of Jella Province has not been carried out yet. Therefore, in this study, visual acuity and the status of the prevalence of refractive errors among primary school children in Jeolla Province in South Korea are assessed.

\section{Materials and methods Sample population}

The local elementary schools in Mokpo city, South Jeolla Province, were notified about the study, and school children from four schools who wanted to participate in this study were recruited. A total of 1,079 elementary school children, aged 8-13 years, who were in the first to sixth grade were selected. Mokpo, with an area of $50.08 \mathrm{~km}^{2}$, is a city in South Jeolla Province in Southwestern Korea. The population was approximately 245,073 (2013), and population density was the tenth highest in South Korea. This region does not pay enough attention to school children's vision and refractions compared to other regions in South Korea. The assessment of visual acuity, objective refraction, and subjective refraction was performed from February to November 2013 in Mokpo, South Korea. Samples were collected from the school children who had no history of eye injuries, and who were not taking any medications. Also, none of the school children had any ocular diseases, and children who were already diagnosed with amblyopia and strabismus that may have an effect on the visual acuity and the refractive status were excluded. Written consent forms were signed and obtained from the subjects' parents and school principals before the examination was performed.

\section{Examination}

Examination included a case history, distance visual acuity, and objective and subjective refraction. The case history includes ocular and systemic conditions as well as symptoms associated with near work taken. Visual acuity test was performed for all subjects. The visual acuity was measured at $5 \mathrm{~m}$ using auto chart project (CCP-3100, Huvitz, Gyeonggi-do, Korea). For all the 1,079 participants, uncorrected visual acuity (UCVA) was determined. UCVA was taken from the upper first line to lower line and recorded as the smallest line read with one or no errors. The right eye was tested first, and the left eye was tested, and then both eyes were tested. When the visual acuity was $<20 / 200$, the auto chart was moved to the distance where it could be read. Four hundred and fifty-six students with own glasses had their corrected visual acuity tested. For these children, visual acuity was measured first with and then without glasses. Refraction was measured with an auto-refractor (HRK-8000A, Huvitz) for each eye for three consecutive times. This was refined by means of a monocular fogging method to a standard end point of maximum plus for best visual acuity. For every student, subjective refraction was measured with phoropter (HDR-7000, Huvitz) and auto chart project (CCP-3100, Huvitz).

\section{Definitions}

Emmetropia was defined as refractive error of between $-0.50 \mathrm{D}$ and $+0.50 \mathrm{D}$ in one or both eyes. Myopia was defined as the spherical equivalent of $-0.50 \mathrm{D}$ or greater in one or both eyes. Myopia was categorized into low myopia $(-0.50 \mathrm{D}$ to $-2.99 \mathrm{D})$, medium myopia ( $-3.00 \mathrm{D}$ to $-5.99 \mathrm{D})$, or high myopia ( $-6.00 \mathrm{D}$ or greater). Hyperopia was defined as the spherical equivalent of greater than $+0.50 \mathrm{D}$ and categorized into low hyperopia (+0.50 D to $1.99 \mathrm{D})$ and medium hyperopia (+2.00 D or more). Astigmatism was defined as a cylinder power equivalent of $0.50 \mathrm{D}$ or greater and equivalent of $1.00 \mathrm{D}$ or greater in at least one eye. Astigmatism was further analyzed by dividing the subjects into three types: myopic astigmatism (simple myopic astigmatism and compound myopic astigmatism), hyperopic astigmatism (simple hyperopic astigmatism and compound hyperopic astigmatism), and mixed astigmatism. Children with myopia in one or both eyes were classified as myopic, and children with hyperopia present in one or both eyes were classified as hyperopic. Emmetropia was classified when neither eye has myopia or hyperopia. Amblyopia was present if bestcorrected visual acuity (BCVA) could not be improved to $>20 / 32$. Anisometropia was defined as difference of spherical equivalent of $1.00 \mathrm{D}$ or greater. Visual impairment was defined as a BCVA equal to or worse than 20/40 in the better eye.

\section{Informed consent and ethical approval procedures}

The local Administration of the Education and School Board was contacted to request their cooperation. After securing permission to perform the study, approval was obtained by the appropriate university ethical advisory committee. Completed consent forms were obtained from the parents or guardians of all children before the examination.

\section{Statistical analysis}

The prevalence rate of refractive errors was calculated in the sample collected. All data were entered into a Microsoft 
Excel database. Analysis was conducted, and prevalence rates were calculated with $95 \%$ confidence intervals (CIs), and followed by frequency analysis, chi-square tests, and multiple regressions, using SPSS (version 21.0 for Windows, IBM Corporation, Armonk, NY). All CIs presented were 95\% CIs, and the significance level was at 0.05 in all analyses.

\section{Results}

\section{Study population}

In this study, 1,079 elementary school children were enumerated and examined, consisting of 543 girls and 536 boys. Table 1 presents the demographic information of the participants in terms of the sex, age, types of refractive errors, and use of corrective glasses. Participants' average age was $10.8 \pm 1.65$ years (range: $8-13$ years), and they were in the first to sixth grade. The prevalence of emmetropia, myopia, hyperopia, and astigmatism was $37.9 \%, 46.5 \%, 6.2 \%$, and $9.4 \%$, respectively. Among all the participants, 456 (42.3\%) were wearing their own corrective spectacles on the date of examination.

\section{Visual acuity}

Table 2 contains the results of visual acuity test, based on UCVA, BCVA, and spectacle-corrected visual acuity. Out of those 1,079 children, 978 (90.6\%) children had an UCVA of $20 / 40$ or worse in better eye, and 61 (5.7\%) children had an UCVA of 20/200 or less in the better eye. UCVA increased

Table I General characteristics of participants in terms of sex, age, refractive error in both eyes, and use of glasses

\begin{tabular}{lll}
\hline & $\mathbf{N}$ & $\%$ \\
\hline Sex & & \\
Boy & 536 & 49.7 \\
Girl & 543 & 50.3 \\
Age (years) & & \\
8 & 124 & 11.5 \\
9 & 157 & 14.6 \\
I0 & 174 & 16.1 \\
II & 196 & 18.2 \\
I2 & 210 & 19.5 \\
I3 & 218 & 20.2 \\
Refractive error & & \\
Emmetropia & 409 & 37.9 \\
Myopia & 502 & 46.5 \\
Hyperopia & 67 & 6.2 \\
Astigmatism & 101 & 9.4 \\
Wearing glasses & & \\
Yes & 456 & 42.3 \\
No & 623 & 57.7 \\
Total & 1,079 & 100.0 \\
\hline Note Data for sex, &
\end{tabular}

Note: Data for sex, age, refractive error, and use of glasses are number examined, with percentage of the total examined. with age $\left(\chi^{2}=46.297, P<0.001\right)$. Two $(0.18 \%)$ children had a BCVA of $\leq 20 / 40$ in better eye, and there were no children with a BCVA of 20/160 to 20/80 in better eye and $\leq 20 / 200$ in the better eye. Amblyopia (defined as BCVA $\leq 20 / 32$ ) was the reason for reduced visual acuity in 22 children $(2.25 \%$ of the 978 ) or $2.03 \%$ of the total study population.

\section{Refractive error}

Table 3 shows the prevalence of refractive error stratified by the age. The prevalence of myopia, hyperopia, and astigmatism was 46.5\% (95\% CI: 43.56-49.5), 6.2\% (95\% CI: 4.92-7.81), and 9.4\% (95\% CI: 7.76-11.25), respectively. Among 124 subjects aged 8 years, 32 presented with myopia, 16 with hyperopia, and seven with astigmatism. Among 157 subjects aged 9 years, 57,15 , and 10 subjects presented with myopia, hyperopia, and astigmatism, respectively. Among 174 subjects aged 10 years, 82, 11, and 18 subjects presented with myopia, hyperopia, and astigmatism, respectively. Among 8- to 10-year olds, number of myopic and astigmatic children was more, whereas the number of hyperopic children was less. Among 11- and 13-year olds, the number of myopic subjects was 107 out of 196 and 127 out of 218 , respectively, and the prevalence rate of astigmatism was $5.6 \%$ (seven out of 124 subjects) and 10.1\% (22 out of 218 subjects), respectively. The prevalence of myopia and astigmatism increased with age but that of hyperopia decreased with age $(P<0.001)$. The increase in the prevalence of astigmatism was statistically significant with age $\left(\chi^{2}=69.474, P<0.001\right)$. In multiple regression analysis, the number of refractive errors was significantly associated with age ( $\beta=0.022,95 \% \mathrm{CI}: 0.01-0.08)$.

Among all the myopic subjects, 77.7\% (95\% CI: 73.74-81.21) had low myopia, $21.3 \%$ (95\% CI: 17.86-25.21) had medium myopia, and 5\% (95\% CI: 0.37-2.45) had high myopia. Table 4 indicates the prevalence of myopia and hyperopia, stratified by age, and the degree of myopia or hyperopia. Medium myopia showed a tendency to increase as the students' age increased from 8 years to 13 years. Among all the hyperopic subjects, low hyperopia occupied 79.1\% (95\% CI: 6.71-87.71), and medium hyperopia occupied 20.9\% (95\% CI: 12.29-32.9). The prevalence of low, medium, and high myopia increased, whereas the rate of low hyperopia decreased with age.

The prevalence of different types of astigmatism is presented in Table 5. The myopic astigmatism showed higher occurrence rate than hyperopic astigmatism. Myopic astigmatism with $\leq-0.50$ D shown was the most prevalent at age 11 and with $\leq-1.00 \mathrm{D}$ showed the highest occurrence 
Table 2 Distribution of UCVA, BCVA, and SCVA in each visual acuity group in terms of percentage and $95 \% \mathrm{Cl}$

\begin{tabular}{|c|c|c|c|c|c|c|}
\hline & \multicolumn{6}{|c|}{ Visual acuity category } \\
\hline & \multicolumn{2}{|c|}{ UCVA } & \multicolumn{2}{|c|}{ BCVA } & \multicolumn{2}{|c|}{ SCVA } \\
\hline & $\mathbf{N}$ & $\% *(\mathrm{Cl})$ & $\mathbf{N}$ & $\%(\mathrm{Cl})$ & $\mathbf{N}$ & $\%$ \\
\hline$\geq 20 / 20$ in better eye & 404 & $37.4(34.6-40.37)$ & 1,047 & 97.0 (95.84-97.89) & - & - \\
\hline $20 / 32-20 / 25$ in better eye & 394 & 36.5 (33.7-39.44) & 28 & $2.6(1.8-3.72)$ & 239 & 60.6 \\
\hline $20 / 63-20 / 40$ in better eye & 180 & $16.7(\mid 4.57-19.02)$ & 4 & $0.4(0.14-0.95)$ & 129 & 71.6 \\
\hline $20 / 160-20 / 80$ in better eye & 40 & $3.7(2.74-5.01)$ & - & - & 32 & 80 \\
\hline$\leq 20 / 200$ in better eye & 61 & $5.7(4.42-7.19)$ & - & - & 56 & 91.8 \\
\hline Total & 1,079 & - & 1,079 & - & 456 & 42.2 \\
\hline
\end{tabular}

Notes: *Data for visual acuities are number examined, with percentage of total examined, and $95 \% \mathrm{Cl}$ is given in parentheses. Data of SCVA are number examined, with percentage of those within each UCVA category.

Abbreviations: UCVA, uncorrected visual acuity; BCVA, best-corrected visual acuity; SCVA, spectacle corrected visual acuity; Cl, confidence interval.

rate at age 13. Interestingly, the prevalence of myopic astigmatism with $\leq-0.50 \mathrm{D}$ distributed almost evenly from 9- to 13-year olds, whereas the prevalence of myopic astigmatism with $\leq-1.00 \mathrm{D}$ increased with subjects' age. Hyperopic astigmatism with $\geq+0.50 \mathrm{D}$ showed the highest occurrence rate at age 10 . Out of 1,079 participants, 101 students presented with astigmatism, which was $9.4 \%$ of total participants, and myopic astigmatism was present in the largest number (90) of students, while the prevalence of different types of astigmatism was not statistically significant with age $\left(\chi^{2}=30.934, P>0.05\right)$.

\section{Discussion}

With a monocular decrease in visual acuity among young children, they rarely complain of vision loss, potentially leading to future vision impairment. ${ }^{21,22}$ In this study, visual impairment, based on BCVA, was prevalent in $0.4 \%$ of the participants. Similar rates were reported in $\operatorname{Iran}^{13}(0.3 \%)$, South Africa ${ }^{23}(0.3 \%)$, and People's Republic of China

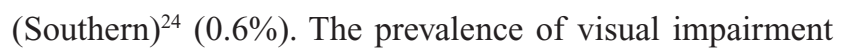
was highest among school children in $\mathrm{Nepal}^{15}(1.4 \%)$, Malaysia $^{16}(1.4 \%)$, and Chile $^{17}(7.4 \%)$. We only included studies with similar definitions of visual impairment. One of the major differences in these studies is the age range and sample size. In some studies, sampling included 5-year-old children, while other studies included 7- to 15-year-old children as sample population. Results from this present study show that the prevalence of visual impairment in children in Jeolla Province, South Korea, is relatively low compared with other countries.

According to our findings, the prevalence of myopia was $46.5 \%$. Similar occurrence rate was found in the People's Republic of China (Guangzhou) ${ }^{8}$ (35.1\%), People's Republic of China (Southern) $)^{24}$ (38.1\%), and Hong Kong 25 (36.7\%). Among all the refractive errors, myopia was the most prevalent, and the prevalence of myopia rapidly increased with the children's age. In He et al's study, similar findings were revealed in the People's Republic of China that myopia was prevalent in $5.7 \%$ of the 5-year-old children and $78.4 \%$ of the 15 -year-old children. ${ }^{24}$ Goh et al also presented that myopia was prevalent in $9.8 \%$ of the 7 -year olds and $34.4 \%$ in 15 -year olds. ${ }^{16}$ In terms of sex, we found no significant difference between boys and girls. Other studies have also found no sex difference in the prevalence of myopia. ${ }^{13,15,17,23}$ The current studies reported that the prevalence of myopia is considerably higher than other refractive errors, and suggested that sex, genes, ethnicity, lifestyle, and environmental factors may affect myopia. ${ }^{27,28}$ In this present study, myopia is

Table 3 Comparison of prevalence of refractive errors ( $95 \% \mathrm{Cls})$ stratified by age

\begin{tabular}{|c|c|c|c|c|c|c|c|c|}
\hline \multirow[t]{2}{*}{ Age (years) } & \multicolumn{2}{|c|}{ Emmetropia } & \multicolumn{2}{|c|}{ Myopia } & \multicolumn{2}{|c|}{ Hyperopia } & \multicolumn{2}{|c|}{ Astigmatism } \\
\hline & $\mathbf{N}$ & $\%$ & $\mathbf{N}$ & $\%$ & $\mathbf{N}$ & $\%$ & $\mathbf{N}$ & $\%$ \\
\hline 8 & 69 & $6.4(5.04-8.06)$ & 32 & $3.0(2.07-4.22)$ & 16 & $1.5(0.88-2.45)$ & 7 & $0.6(0.29-1.4)$ \\
\hline 9 & 75 & $7.0(5.54-8.68)$ & 57 & $5.3(4.06-6.83)$ & 15 & I.4 (0.8I-2.34) & 10 & $0.9(0.47-1.76)$ \\
\hline 10 & 63 & $5.8(4.55-7.45)$ & 82 & $7.6(6.12-9.39)$ & II & $1.0(0.54-1.88)$ & 18 & $1.7(1.02-2.68)$ \\
\hline II & 59 & $5.4(4.22-7.04)$ & 107 & 9.9 (8.23-1 I.9) & 9 & $0.8(0.4-1.63)$ & 22 & $2.0(1.3 \mid-3.12)$ \\
\hline 12 & 83 & 7.7 (6.2-9.48) & 97 & $9.0(7.38-10.9)$ & 8 & $0.7(0.34-1.52)$ & 22 & $2.0(1.31-3.12)$ \\
\hline 13 & 61 & $5.7(4.38-7.24)$ & 127 & II.8 (9.94-13.88) & 8 & $0.7(0.34-1.52)$ & 22 & $2.0(1.31-3.12)$ \\
\hline Total & 409 & $37.9(35.06-40.84)$ & 502 & $46.5(43.56-49.5)$ & 67 & $6.2(4.92-7.8 I)$ & 101 & $9.4(7.76-11.25)$ \\
\hline
\end{tabular}

Note: Data are number examined, with percentage of the total examined, and $95 \% \mathrm{Cl}$ is given in parentheses.

Abbreviation: $\mathrm{Cl}$, confidence interval. 
Table 4 Prevalence of myopia and hyperopia stratified by age

\begin{tabular}{|c|c|c|c|c|c|c|c|c|c|c|}
\hline \multirow{3}{*}{$\begin{array}{l}\text { Age } \\
\text { (years) }\end{array}$} & \multicolumn{6}{|c|}{ Myopia } & \multicolumn{4}{|c|}{ Hyperopia } \\
\hline & \multicolumn{2}{|c|}{ Low } & \multicolumn{2}{|c|}{ Medium } & \multicolumn{2}{|c|}{ High } & \multicolumn{2}{|c|}{ Low } & \multicolumn{2}{|c|}{ Medium } \\
\hline & $\mathbf{N}$ & $\%(\mathrm{Cl})$ & $\mathbf{N}$ & $\%(\mathrm{Cl})$ & $\mathbf{N}$ & $\%(\mathrm{Cl})$ & $\mathbf{N}$ & $\%(\mathrm{Cl})$ & $\mathbf{N}$ & $\%(\mathrm{Cl})$ \\
\hline 8 & 27 & $5.4(3.64-7.83)$ & 5 & $1.0(0.37-2.45)$ & 0 & - & 13 & $19.4(11.12-31.24)$ & 3 & $4.5(11.6-13.38)$ \\
\hline 9 & 41 & $8.2(5.99-11.01)$ & 16 & $3.2(1.9-5.24)$ & 0 & - & 12 & 17.9 (9.99-29.59) & 3 & 4.5 (II.6-13.38) \\
\hline 10 & 60 & $12.0(9.31-15.19)$ & 21 & $4.2(2.67-6.42)$ & 1 & $0.2(0.01-1.28)$ & 10 & I 4.9 (7.77-26.2I) & 1 & $1.5(0.08-9.13)$ \\
\hline II & 89 & I7.7 (I4.55-2I.42) & 17 & $3.4(2.05-5.48)$ & I & $0.2(0.0 \mathrm{I}-\mathrm{I} .28)$ & 8 & II.9 (5.66-22.72) & I & $1.5(0.08-9.13)$ \\
\hline 12 & 70 & I3.9 (II.09-|7.35) & 26 & $5.2(3.48-7.6)$ & I & $0.2(0.0 \mathrm{I}-\mathrm{I} .28)$ & 6 & $9.0(3.7-19.12)$ & 2 & $3.0(0.52-\mid I .32)$ \\
\hline 13 & 103 & $20.5(17.12-24.38)$ & 22 & $4.4(2.83-6.66)$ & 2 & $0.4(0.07-1.6)$ & 4 & $6.0(1.93-15.35)$ & 4 & $6.0(1.93-15.35)$ \\
\hline Total & 390 & 77.7 (73.74-8I.2I) & 107 & $21.3(17.86-25.21)$ & 5 & $1.0(0.37-2.45)$ & 53 & 79.1 (6.7I-87.7I) & 14 & $20.9(12.29-32.9)$ \\
\hline
\end{tabular}

Note: Data are number examined, with percentage of the total examined, and $95 \% \mathrm{Cl}$ is given in parentheses.

Abbreviation: $\mathrm{Cl}$, confidence interval.

the major refractive error in school children, and this could be due to lifestyle and study environment that may effect on the prevalence of myopia.

In this study, the prevalence of hyperopia was $6.2 \%$, whereas various studies report on the prevalence of hyperopia as $16.6 \%$ and $0.8 \%$ in India ${ }^{26}$ and Iran, ${ }^{13}$ respectively. In our study, the prevalence of hyperopia decreased with age, and this tendency of decreasing prevalence of hyperopia was also reported by previous studies such as those in Nepal ${ }^{15}$ and Malaysia. ${ }^{16}$ The reason for hyperopia decreasing with age in children may be the part of emmetropization process. ${ }^{27,29}$

The prevalence of low myopia was higher than high myopia in our study. The reason for this result can be related to subjects' age. Myopia in young children usually starts developing during the age of 11-13 years. Since the prevalence of high myopia increased with age, one can assume that the prevalence of high myopia in our study will further increase when the children get older; thus, it is necessary to warrant that the future study will include children younger than 8 years and older than 13 years to assess the status of refractive errors.

Astigmatism was seen in $9.4 \%$ of the sample population. Relatively higher prevalence of astigmatism has been reported in the People's Republic of China (Guangzhou) ${ }^{8}$ (33.6\%), Chile $^{17}(27 \%)$, and People's Republic of China (Southern) $)^{21}$ $(42.7 \%)$ in subjects aged 5-15 years. Also, the lower occurrence rate of astigmatism has been reported in $\mathrm{Nepal}^{15}(3.5 \%)$ and $\operatorname{India}^{26}(9.7 \%)$ in subjects aged $7-16$ years. One of the most important reasons for the higher prevalence of astigmatism has probably been reported in East Asian countries to be genetic factor. ${ }^{23} \mathrm{Also}$, in the case of myopia and astigmatism, factors considered to tend to increase the prevalence include a high level of educational enthusiasm and an intensive learning environment. For instance, the prolonged near work activities can have an effect on increasing prevalence of myopia and astigmatism. The age reported in the study is an important period of growth as well as cognitive, social, and physical development of children. If refractive errors and visual impairment occur in elementary school children, they could cause the inhibition of growth and development as well as learning disabilities. Therefore, it is very important to understand the status of refractive errors in children. However, further studies are needed to ascertain the correlation of prevalence of myopia and astigmatism and studying intensity. Also, the environmental factors, such as urban or rural area of survey, and socioeconomic status need to be determined in the future.

Table 5 Prevalence of different types of astigmatism

\begin{tabular}{|c|c|c|c|c|c|c|c|c|c|c|}
\hline \multirow{3}{*}{$\begin{array}{l}\text { Age } \\
\text { (years) }\end{array}$} & \multicolumn{4}{|c|}{ Myopic astigmatism } & \multicolumn{4}{|c|}{ Hyperopic astigmatism } & \multicolumn{2}{|c|}{ Mixed astigmatism } \\
\hline & \multicolumn{2}{|c|}{$\leq-0.50 \mathrm{D}$} & \multicolumn{2}{|c|}{$\leq-1.00 \mathrm{D}$} & \multicolumn{2}{|c|}{$\geq+0.50 \mathrm{D}$} & \multicolumn{2}{|c|}{$\geq+1.00 \mathrm{D}$} & & \\
\hline & $\mathbf{N}$ & $\%(\mathrm{Cl})$ & $\mathbf{N}$ & $\%(\mathrm{Cl})$ & $\mathbf{N}$ & $\%(\mathrm{Cl})$ & $\mathbf{N}$ & $\%(\mathrm{Cl})$ & $\mathbf{N}$ & $\%(\mathrm{Cl})$ \\
\hline 8 & 3 & $3.0(0.77-9.06)$ & 4 & $4.0(1.28-10.4 I)$ & 0 & - & 0 & - & 0 & - \\
\hline 9 & 7 & $6.9(3.07-14.24)$ & 1 & $1.0(0.05-6.18)$ & 1 & $1.0(0.05-6.18)$ & 1 & $1.0(0.05-6.18)$ & 0 & - \\
\hline 10 & 6 & $5.9(2.44-12.99)$ & 8 & $7.9(3.73-15.47)$ & 4 & $4.0(1.28-10.4 I)$ & 0 & - & 0 & - \\
\hline II & 10 & $9.9(5.11-17.87)$ & 11 & $10.9(5.83-19.04)$ & I & $1.0(0.05-6.18)$ & 0 & - & 0 & - \\
\hline 12 & 8 & $7.9(3.73-15.47)$ & II & $10.9(5.83-19.04)$ & 2 & $2.0(0.34-7.66)$ & 0 & - & I & $1.0(0.05-6.18)$ \\
\hline 13 & 7 & $6.9(3.07-14.24)$ & 14 & $13.9(8.06-22.5)$ & 0 & - & 0 & - & I & $1.0(0.05-6.18)$ \\
\hline Total & 41 & $40.6(31.07-50.83)$ & 49 & $48.5(38.52-58.6 I)$ & 8 & $7.9(3.73-15.47)$ & 1 & $1.0(0.05-6.18)$ & 2 & $2.0(0.34-7.66)$ \\
\hline
\end{tabular}

Note: Data are number examined, with percentage of the total examined, and $95 \% \mathrm{Cl}$ is given in parentheses.

Abbreviations: $\mathrm{D}$, diopter; $\mathrm{Cl}$, confidence interval. 


\section{Conclusion}

The prevalence of myopia in Korean elementary school children increased with age. The present study reveals a considerably higher prevalence of refractive errors among elementary school children in South Jeolla Province of South Korea, exceeding 50\% of subjects. Myopia was the most prevalent in the school children in Korea, which is similar to many other countries including People's Republic of China, Malaysia, and Hong Kong. The prevalence of astigmatism increased with age. This may indicate that genetics and educational influences, such as studying and learning, may play a role in the progression of myopia in Korean elementary school children. However, prevalence of hyperopia decreased as children age, and this tendency can be due to part of emmetropization. Therefore, it is salient to have frequent vision testing and refraction measured in accordance with increasing tendency of myopia and astigmatism.

\section{Disclosure}

The authors report no conflicts of interest in this work.

\section{References}

1. Resnikoff S, Pascolini D, Mariotti SP, Pokharel GP. Global magnitude of visual impairment caused by uncorrected refractive errors in 2004. Bull World Health Organ. 2008;86:63-70.

2. Pizzarello L, Abiose A, Ffytche T, et al. Vision 2020: the right to sight: a global initiative to eliminate avoidable blindness. Arch Ophthalmol. 2004; 122:615-620.

3. Gupta A, Casson RJ, Newland HS, et al. Prevalence of refractive error in rural Myanmar: the Meiktila Eye Study. Ophthalmology. 2008;115: 26-32.

4. Saw SM, Gazzard G, Koh D, et al. Prevalence rates of refractive errors in Sumatra, Indonesia. Invest Ophthalmol Vis Sci. 2002;4: 3174-3180

5. Wong TY, Foster PJ, Hee J, et al. Prevalence and risk factors for refractive errors in adult Chinese in Singapore. Invest Ophthalmol Vis Sci. 2000;41:2486-2494.

6. Hashemi H, Fotouhi A, Mohammand K. The age- and gender-specific prevalences of refractive errors in Tehran: the Tehran Eye Study. Ophthalmic Epidemiol. 2004;11:213-225.

7. Anera RG, Soler M, Cruz CJ, Salas C, Ortiz C. Prevalence of refractive errors in school-age children in Morocco. Clin Experiment Ophthalmol. 2009;37:191-196.

8. He MG, Lin Z, Huang J, Lu Y, Wu CF, Wu JJ. Population-based survey of refractive error in school-aged children in Liwan District, Guangzhou. Zhonghua Yan Ke Za Zhi. 2008;44:491-496.

9. Ip JM, Robaei D, Rochtchina E, Mitchell P. Prevalence of eye disorders in young children with eyestrain complaints. Am J Ophthalmol. 2006;142:495-497.

10. Dandona L, Dandona R. Estimation of global visual impairment due to incorrected refractive error. Bull World Health Organ. 2008;86:B-C.
11. Zhao J, Pan X, Sui R, Munoz SR, Sperduto RD, Ellwein LB. Refractive Error Study in Children: results from Shunyi District, China. Am J Ophthalmol. 2000;129:427-435.

12. Wu JF, Bi HS, Wang SM, et al. Refractive error, visual acuity and causes of vision loss in children in Shandong, China. The Shandong Children Eye Study. PLoS One. 2013;8(12):e82763.

13. Fotouhi A, Hashemi H, Khabazkhoob M, Mohammad K. The prevalence of refractive errors among schoolchildren in Dezful, Iran. $\mathrm{Br} J$ Ophthalmol. 2007;91:287-292.

14. Lin LL, Shin YF, Tasi CB, Chen CJ, Lee LA. Epidemiology study of ocular refraction among schoolchildren in Taiwan 1995. Optom Vis Sci. 1999;76(5):275-281.

15. Pokharel GP, Negrel AD, Munoz SR, Ellwein LB. Refractive Error Study in Children: results from MechiZone, Nepal. Am J Ophthalmol. 2000;129:436-444.

16. Goh PP, Abqariyah Y, Pokharel GP, Ellwein LB. Refractive error and visual impairment in school age children in Gombak District Malaysia. Ophthalmology. 2005;112:678-685.

17. Maul E, Barroso S, Munoz SR, Sperduto RD, Ellwein LB. Refractive Error Study in Children: results from La Florida, Chile. Am J Ophthalmol. 2000;129:445-454.

18. Jung SK, Lee JH, Kakizaki H, Jee D. Prevalence of myopia and its association with body stature and educational level in 19 year old male conscripts in Seoul South Korea. Invest Ophthalmol Vis Sci. 2012;53: 5579-5583.

19. Lee JH, Jee DH, Kwon JW, Lee WK. Prevalence and risk factor for myopia in a rural Korean population. Invest Ophthalmol Vis Sci. 2013;54:5466-5471.

20. Lee SJ, Urm SH, Yu BC. The prevalence of high myopia in 19 yearold men in Busan, Ulsan and Gyeongsangnam-do. J Prev Med Public Health. 2011;44:56-64.

21. Tong L, Saw SM, Tan D, et al. Sensitivity and specificity of visual acuity screening for refractive errors in school children. Optom Vis Sci. 2002;79(10):650-657.

22. Schmidt P, Maguire M, Dobson V, et al; Vision in Preschoolers Study Group. Vision in preschoolers study group: comparison of preschool vision screening tests as administered by licensed eye care professionals in the vision in preschoolers study. Ophthalmology. 2004;111(4): $637-650$.

23. Naidoo KS, Raghunandan A, Mashige KP, et al. Refractive error and visual impairment in Africa children in South Africa. Invest Ophthalmol Vis Sci. 2003;44:3764-3770.

24. He M, Zeng J, Liu Y, Xu J, Pokharel GP, Ellwein LB. Refractive error and visual impairment in urban children in Southern China. Invest Ophthalmol Vis Sci. 2004;45:793-799.

25. Fan DS, Lam DS, Lam RF, et al. Prevalence, incidence, and progression of myopia of school children in Hong Kong. Invest Ophthalmol Vis Sci. 2004;45:1071-1075.

26. Dandona R, Dandona L, Srinivas M, et al. Refractive error in children in a rural population in India. Invest Ophthalmol Vis Sci. 2002;43: 615-622.

27. Twelker JD, Mitchell GL, Messer DH, et al; CLEERE Study Group. Children's ocular components and age, gender, and ethnicity. Optom Vis Sci. 2009;86:918-935.

28. Morgan I, Rose K. How genetic is school myopia? Prog Retin Eye Res. 2005;24:1-38.

29. Jones LA, Mitchell GL, Mutti DO, Hayes JR, Moeschberger ML, Zadnik K. Comparison of ocular component growth curves among refractive error groups in children. Invest Ophthalmol Vis Sci. 2005;46: 2317-2327. 


\section{Publish your work in this journal}

Clinical Optometry is an international, peer-reviewed, open access journal publishing original research, basic science, clinical and epidemiologica studies, reviews and evaluations on clinical optometry. All aspects of patient care are addressed within the journal as well as the practice of optometry including economic and business analyses. Basic and clinical

Submit your manuscript here: http://www.dovepress.com/clinical-optometry-journal

\section{Dovepress}

research papers are published that cover all aspects of optics, refraction and its application to the theory and practice of optometry. The manuscript management system is completely online and includes a very quick and fair peer-review system, which is all easy to use. Visit http://www.dovepress. com/testimonials.php to read real quotes from published authors. 